\title{
Numerical Procedure for Optimizing Dye-Sensitized Solar Cells
}

\author{
Mihai Razvan Mitroi, ${ }^{1}$ Laurentiu Fara, ${ }^{1,2}$ and Magdalena Lidia Ciurea ${ }^{2,3}$ \\ ${ }^{1}$ University Politehnica of Bucharest, 313 Splaiul Independentei, 060042 Bucharest, Romania \\ ${ }^{2}$ Academy of Romanian Scientists, 54 Splaiul Independentei, 050094 Bucharest, Romania \\ ${ }^{3}$ National Institute of Materials Physics, 105 bis Atomistilor Street, P.O. Box MG-7, 077125 Magurele, Romania \\ Correspondence should be addressed to Magdalena Lidia Ciurea; ciurea@infim.ro
}

Received 23 July 2013; Revised 13 November 2013; Accepted 29 November 2013; Published 5 January 2014

Academic Editor: Hyeong-Ho Park

Copyright (C) 2014 Mihai Razvan Mitroi et al. This is an open access article distributed under the Creative Commons Attribution License, which permits unrestricted use, distribution, and reproduction in any medium, provided the original work is properly cited.

We propose a numerical procedure consisting of a simplified physical model and a numerical method with the aim of optimizing the performance parameters of dye-sensitized solar cells (DSSCs). We calculate the real rate of absorbed photons (in the dye spectral range) $G_{\text {real }}(x)$ by introducing a factor $\beta<1$ in order to simplify the light absorption and reflection on TCO electrode. We consider the electrical transport to be purely diffusive and the recombination process only to occur between electrons from the $\mathrm{TiO}_{2}$ conduction band and anions from the electrolyte. The used numerical method permits solving the system of differential equations resulting from the physical model. We apply the proposed numerical procedure on a classical DSSC based on Ruthenium dye in order to validate it. For this, we simulate the $J-V$ characteristics and calculate the main parameters: short-circuit current density $J_{s c}$, open circuit voltage $V_{\mathrm{oc}}$, fill factor FF, and power conversion efficiency $\eta$. We analyze the influence of the nature of semiconductor $\left(\mathrm{TiO}_{2}\right)$ and dye and also the influence of different technological parameters on the performance parameters of DSSCs. The obtained results show that the proposed numerical procedure is suitable for developing a numerical simulation platform for improving the DSSCs performance by choosing the optimal parameters.

\section{Introduction}

The technology and materials used for the third generation solar cells give the opportunity to obtain cells with high efficiency [1-5]. The solar cells based on dye-sensitized nanostructure with mesoporous metal oxides (DSSCs) have attracted considerable attention since the work of O'Regan and Grätzel [6], their manufacturing being environmentfriendly and energy-efficient $[1,7]$. Up to now, certified efficiencies over $10 \%$ under standard conditions or even higher $(12,4 \%)$ at the laboratory scale were reported [7-10]. Based on the low cost of materials and the simplicity of fabrication process, DSSC can have lower fabrication costs than conventional silicon-based solar cells. Taking into account this advantage, the improvement of DSSC parameters for making them widely used appears as a strong necessity.

Further optimization of the DSSC parameters requires a better correlation between interrelated processes of transport and accumulation of electrons in the mesoporous oxide phase and recombination of electrons with electron acceptors [11]. In order to understand the different processes governing the DSSC's mode of operation and to enhance the DSSCs performance, modeling of processes and numerical simulation of the cells were carried out [12-23]. The thickness, morphology (particle diameter and porosity) for the $\mathrm{TiO}_{2}$ layer, electron mobility and recombination rate (electron lifetime), absorption spectrum of the dye, thickness and material quality of transparent conductive oxide (TCO) layers and the used electrolyte determine the $J-V$ characteristics [17, $18,20-22,24]$. Consequently, the extracted parameters from simulation, the short-circuit current density $J_{s c}$, the open circuit voltage $V_{\mathrm{oc}}$, the fill factor $\mathrm{FF}$, and the power conversion efficiency $\eta$ were analyzed.

In the present paper, we propose a numerical procedure for optimizing the DSSCs consisting of a simplified physical model and a numerical method capable of solving the system of differential equations resulted from the physical model. We applied this proposed procedure on a DSSC with Ru dye 
in order to show its validity. For this, the current densityvoltage $(J-V)$ characteristics were simulated, and the main parameters $J_{\mathrm{sc}}, V_{\mathrm{oc}}, \mathrm{FF}$, and $\eta$ were obtained and discussed. The influence of the thickness of $\mathrm{TiO}_{2}$ film and electron lifetime on the cell performance parameters was analyzed aiming to be used in the cell manufacturing.

\section{Physical Model and Numerical Method}

We use a classical DSSC which is presented in Figure 1. This device contains two electrodes made of TCO glass, commonly used being fluorine-doped tin oxide (FTO). The illuminated electrode is coated with a nanoporous $\mathrm{TiO}_{2}$ layer which is also coated with a monolayer of the Ru-complex dye. On the counter electrode of TCO glass, a thin layer of Pt $(\sim 5 \mathrm{~nm})$ which acts as a catalyst for the redox reaction is deposited [25]. The space between the two electrodes is filled with an electrolyte (propyl methyl imidazolium iodide) containing an iodide/triiodide $\left(I^{-} / I_{3}^{-}\right)$redox couple.

In a DSSC under visible light, an electron from the dye molecule is excited, then injected into the conduction band of $\mathrm{TiO}_{2}$ nanostructured semiconductor, and finally collected by the TCO glass electrode and transported in the external load. The positive charge (dye cations) is reduced by receiving an electron from the iodide ion $\left(I^{-}\right)$which will be subsequently regenerated by reducing triiodide ions $\left(I_{3}^{-}\right)$at the platinized counter electrode.

By using the nanostructured $\mathrm{TiO}_{2}$, the depletion process is less pronounced, so that under reverse bias the electric field is negligible $[14,26]$. The origin of the photovoltage is explained by a built-in potential barrier between $\mathrm{TiO}_{2}$ semiconductor and the TCO electrode and/or by changing the position of Fermi level due to the electron injection [26]. The most probable recombination process takes place between electrons from $\mathrm{TiO}_{2}$ and $I_{3}^{-}$ions $[18,19]$.

In the ideal case, the rate of the absorbed photons in the volume unit can be written as

$$
G_{\text {ideal }}(x)=\int_{\lambda_{1}}^{\lambda_{2}} \alpha(\lambda) \phi_{\text {ideal }}(\lambda) \exp [-\alpha(\lambda) \cdot x] d \lambda,
$$

where $x \in[0, d]$ describes the position inside the $\mathrm{TiO}_{2}$ film (including the dye) with a thickness $d, \lambda$ is the wavelength of the radiation, limits $\lambda_{1}$ and $\lambda_{2}$ are imposed by the absorption characteristics of the dye through the absorption coefficient $\alpha(\lambda)$, and $\phi_{\text {ideal }}(\lambda)$ is the spectral incident photon flux density.

In the real case, the rate of the absorbed photons $G_{\text {ideal }}(x)$ in the volume unit is reduced to $G_{\text {real }}(x)$ due to the light absorption in TCO glass electrodes and to the reflection onto [16]. We describe the contributions of these processes by a factor $\beta<1$ aiming to propose a simplified model to be used for designing and optimizing any type of DSSCs. Therefore, $G_{\text {real }}(x)$ is given by

$$
G_{\text {real }}(x)=\beta \cdot G_{\text {ideal }}(x) .
$$

The rate of electron injection $G_{\text {inj }}(x)$ should take into account the injection efficiency $\eta_{\text {inj }}[11]$, so that

$$
G_{\text {inj }}(x)=\eta_{\text {inj }} \cdot G_{\text {real }}(x) \text {. }
$$

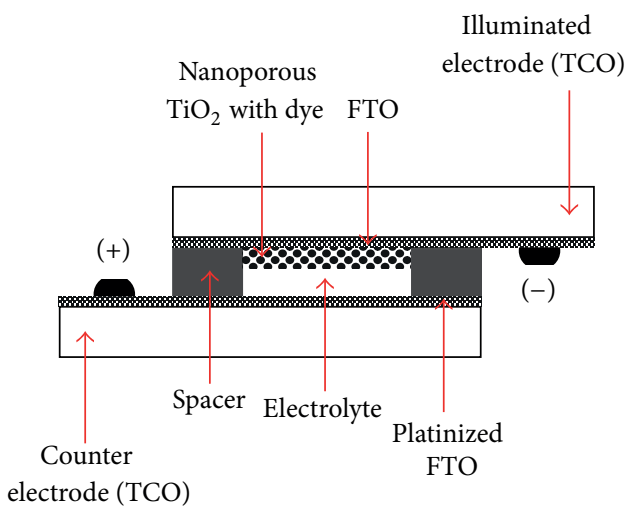

FIGURE 1: Sketch of a classical DSSC. Nanoporous $\mathrm{TiO}_{2}$ with dye has $d$ thickness.

In our simplified model we consider the electrical transport to be purely diffusive, and therefore it is described by a diffusive transport equation for the electrical current density $J[17,19]$. We neglect the internal electric field generated by unbalanced local charge because of its very low value [12, 17]. The electron density $n(x)$ in the conduction band of the $\mathrm{TiO}_{2}$ layer is described by the continuity equation in quasistationary regime. In this case, the system of equations has the following form:

$$
\begin{gathered}
-\frac{1}{e} \frac{d J(x)}{d x}=G_{\text {inj }}(x)-R(x), \\
J(x)=e D \frac{d n(x)}{d x},
\end{gathered}
$$

where $e$ is the elementary charge, $x$ describes the position inside the $\mathrm{TiO}_{2}$ film $x \in[0, d], R(x)$ is the recombination rate, and $D$ is the electron diffusion coefficient.

We neglect the trapping/detrapping processes, so that in the continuity equation (see (4)) the corresponding terms do not appear [15]. Also we assume that the recombination process takes place only between electrons from conduction band of $\mathrm{TiO}_{2}$ layer and anions present in the electrolyte [18]. Consequently, the recombination rate is proportional to $n(x)-n_{0}$, so that

$$
R(x)=\frac{n(x)-n_{0}}{\tau}
$$

where $n_{0}$ is the electron density at equilibrium (in the dark) and $\tau$ is the electron lifetime.

The boundary conditions are the following.

(1) Assuming that electrons are extracted by application of an external voltage $V$, the boundary condition at $x=0$ is

$$
\left.n(x)\right|_{x=0}=N_{c} \exp \left(-\frac{E-e V}{k_{B} T}\right)
$$


where $N_{c}$ is the density of states in the conduction band of $\mathrm{TiO}_{2}$ semiconductor, given by the formula

$$
N_{c}=2\left(\frac{2 \pi m_{e}^{*} k_{B} T}{h^{2}}\right)^{3 / 2}
$$

where $m_{e}^{*}$ is the effective mass of the electron, $k_{B}$ is Boltzmann constant, $h$ is Planck constant, $T$ is the cell temperature, and $E=E_{c}-E_{F}$ is the energy between the conduction band edge $E_{c}$ and the Fermi quasilevel $E_{F}$.

(2) Assuming that all the electrons are collected at $x=d$ (there is no recombination process inside $\mathrm{TiO}_{2}$ film meaning that $\mathrm{TiO}_{2}$ film has a good quality from the technological point of view), the boundary condition at $x=d$ is

$$
\left.\frac{d n(x)}{d x}\right|_{x=d}=0
$$

The open circuit voltage $V_{\mathrm{oc}}$ is derived from the condition $J=0$ and is given by the expression

$$
V_{\mathrm{oc}}=\frac{k_{B} T \ln \left(\left(\tau \cdot G_{\mathrm{inj}}(0)+n_{0}\right) / N_{c}\right)+E}{e},
$$

where $G_{\text {inj }}(0)$ is the rate of electron injection at $x=0$, while the short-circuit current density $J_{\mathrm{sc}}$ is obtained for the condition $V=0$.

The system of differential equations (4) and (5) together with boundary conditions (see (7) and (9)) has no enough conditions at $x=0$ but has the boundary condition at $x=$ $d$ (see (9)). This problem is known as "the boundary value problem," being defined by differential equations in which some conditions are specified at the initial point while the others are specified at the end point. In order to solve this system, we used a numerical method based on the "shooting method" [27] which generates different values for the initial condition at $x=0$ until the final condition at $x=d$ is satisfied. We used this method in a program developed in Mathcad.

Consequently, the numerical procedure we propose for designing and optimizing any type of DSSCs considers the essential processes which occur in a real DSSC and its technological parameters and simplifies the others, for example, the contribution of the light absorption and reflection on the TCO electrodes by introducing $\beta<1$ for obtaining $G_{\text {real }}(x)$.

\section{Results and Discussion}

In order to validate our numerical procedure (simplified model and numerical method) we apply it on a DSSC based on $\mathrm{Ru}$ dye and simulate the $J-V$ characteristics. For this, we took into account the absorption coefficient $\alpha(\lambda)$ of the Ru dye between the spectral limits $\lambda_{1}=300 \mathrm{~nm}$ and $\lambda_{2}=$ $800 \mathrm{~nm}$ where its absorption is very $\operatorname{good}\left(\sim 10^{3} \mathrm{M}^{-1} \mathrm{~cm}^{-1}\right)$ [28]. The numerical procedure can be applied on a DSSC based on a different dye by changing the spectral limits and
TABLE 1: The constants and parameters used in simulation.

\begin{tabular}{lc}
\hline Parameters & Value \\
\hline$m_{e}^{*}$ & $5.6 m_{e}\left(m_{e}=\right.$ electron mass $)$ \\
$T$ & $300 \mathrm{~K}$ \\
$n_{0}$ & $10^{17} \mathrm{~cm}^{-3}$ \\
$E=E_{c}-E_{F}$ & $0.9 \mathrm{eV}$ \\
$\eta_{\text {inj }}$ & 0.95 \\
$D$ & $5 \cdot 10^{-5} \mathrm{~cm}^{2} / \mathrm{s}$ \\
\hline
\end{tabular}

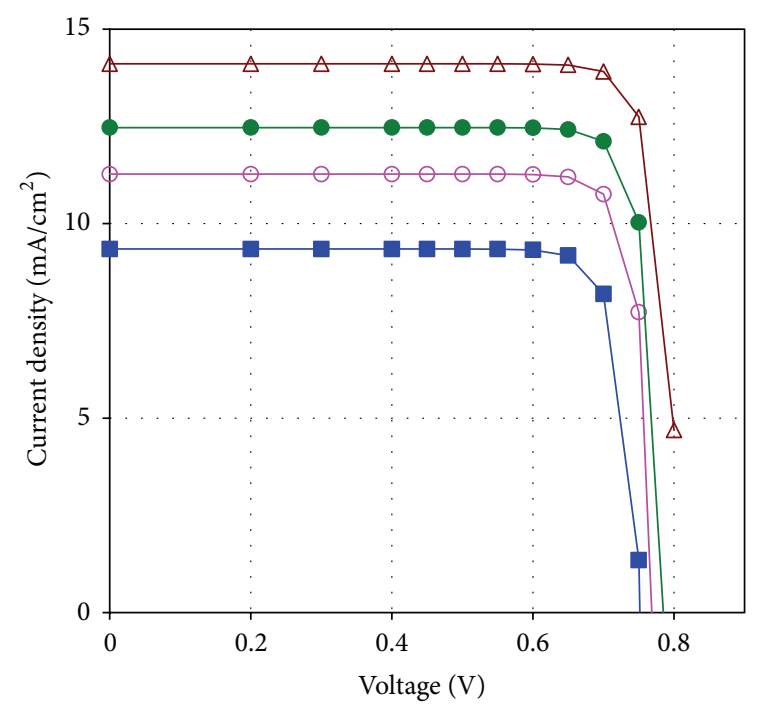

Figure 2: $J-V$ characteristics obtained for $\eta_{\text {inj }}=0.95, D=5$. $10^{-5} \mathrm{~cm}^{2} / \mathrm{s}, \beta=0.9$, and $d=20 \mu \mathrm{m}$ and for different values of the electron lifetime $\tau$ : $\tau=2 \mathrm{~ms} ; \mathrm{o} \tau=10 \mathrm{~ms} ; \boldsymbol{\tau}=20 \mathrm{~ms} ; \Delta \tau=50 \mathrm{~ms}$.

TABLE 2: The values of $J_{\mathrm{sc}}, V_{\mathrm{oc}}, \mathrm{FF}$, and $\eta$ obtained for different $\beta$.

\begin{tabular}{lcccc}
\hline$\beta$ & $J_{\mathrm{sc}}\left(\mathrm{mA} / \mathrm{cm}^{2}\right)$ & $V_{\mathrm{oc}}(\mathrm{mV})$ & $\mathrm{FF}$ & $\eta(\%)$ \\
\hline 0.8 & 11.170 & 819 & 0.828 & 7.572 \\
0.9 & 12.470 & 822 & 0.828 & 8.482 \\
0.95 & 13.120 & 823 & 0.827 & 8.937 \\
1 & 13.770 & 824 & 0.827 & 9.392 \\
\hline
\end{tabular}

the absorption coefficient. For the incident flux density we considered the AM1.5 G spectrum [29]. The other constants and parameters used in the simulation were taken from the literature $[11,12,21]$ and are presented in Table 1.

Figure 2 shows the simulated $J$ - $V$ characteristics obtained for $d=20 \mu \mathrm{m}$ and $\beta=0.9$ and different values for the electron lifetime $\tau$ in the conduction band.

The values obtained for $J_{\mathrm{sc}}, V_{\mathrm{oc}}, \mathrm{FF}$, and $\eta$ using the parameters $\tau=20 \mathrm{~ms}$ and $d=20 \mu \mathrm{m}$ and different values for $\beta$ are listed in Table 2 . One can see that an increase of $\beta$ with $20 \%$ (by using suitable TCO electrodes) produces an increase of both $J_{\text {sc }}$ and $\eta$ with about $24 \%$, while $V_{\text {oc }}$ and FF remain practically constant.

The simulated values for $J_{\mathrm{sc}}, V_{\mathrm{oc}}, \mathrm{FF}$, and $\eta$ as a function of the $\mathrm{TiO}_{2}$ film thickness, using $\tau=20 \mathrm{~ms}$, are presented in Table 3. According to this, Figures 3(a) and 3(b) present the 


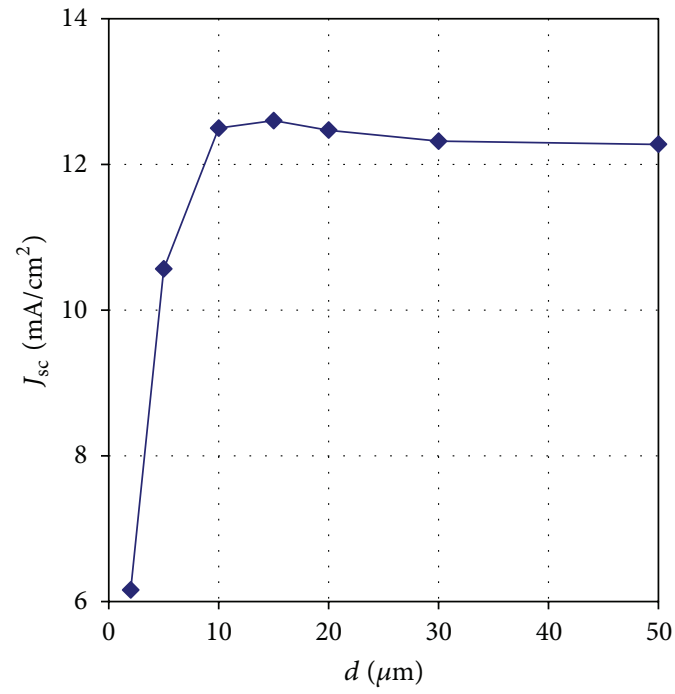

(a)

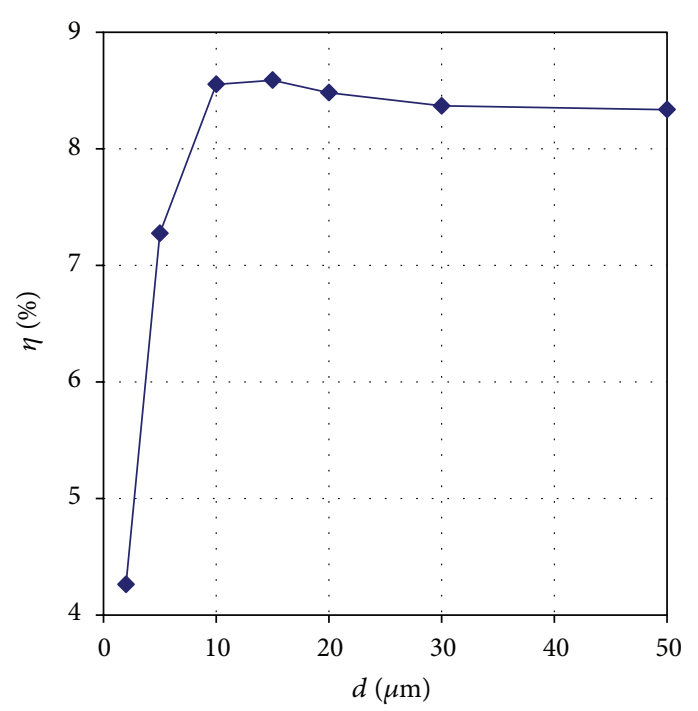

(b)

Figure 3: The thickness dependence of $J_{\mathrm{sc}}$ (a) and $\eta(\mathrm{b})$, calculated for $\eta_{\mathrm{inj}}=0.95, D=5 \cdot 10^{-5} \mathrm{~cm}^{2} / \mathrm{s}, \beta=0.9$, and $\tau=20 \mathrm{~ms}$.

TABLE 3: The values of $J_{\mathrm{sc}}, V_{\mathrm{oc}}, \mathrm{FF}$, and $\eta$ obtained for different $\mathrm{TiO}_{2}$ thicknesses.

\begin{tabular}{lcccc}
\hline$d(\mu \mathrm{m})$ & $J_{\mathrm{sc}}\left(\mathrm{mA} / \mathrm{cm}^{2}\right)$ & $V_{\mathrm{oc}}(\mathrm{mV})$ & $\mathrm{FF}$ & $\eta(\%)$ \\
\hline 2 & 6.160 & 822 & 0.842 & 4.262 \\
5 & 10.564 & 822 & 0.838 & 7.276 \\
10 & 12.498 & 822 & 0.833 & 8.553 \\
15 & 12.601 & 822 & 0.830 & 8.589 \\
20 & 12.470 & 822 & 0.828 & 8.482 \\
30 & 12.320 & 822 & 0.827 & 8.369 \\
50 & 12.275 & 822 & 0.826 & 8.336 \\
\hline
\end{tabular}

thickness dependence of the short-circuit current density $J_{\text {sc }}$ and the power conversion efficiency $\eta$, the $\mathrm{TiO}_{2}$ film thickness being an important technological parameter for designing and optimizing the cell. One can see that both $J_{\mathrm{sc}}$ and $\eta$ increase with the film thickness up to maximum values of $J_{\text {sc }}=12.601 \mathrm{~mA} / \mathrm{cm}^{2}$ and $\eta=8.589 \%$, respectively, reached for $d=15 \mu \mathrm{m}$. By further increasing the film thickness up to $50 \mu \mathrm{m}$, they insignificantly decrease (2\%-3\%). Consequently, a thicker layer will not bring any improvement to $J_{\mathrm{sc}}$ or $\eta$ (helpful information for design and technological processes). Also, one can observe that the increase of film thickness from 2 to $10 \mu \mathrm{m}$ does not influence the open circuit voltage $V_{\mathrm{oc}}$ (remains constant) and the fill factor FF (decreases with about $2 \%)$.

In Table 4 the values for $J_{\mathrm{sc}}, V_{\mathrm{oc}}, \mathrm{FF}$, and $\eta$ calculated for different values of the lifetime $\tau$ using $d=20 \mu \mathrm{m}$ are given. Figures 4(a) and 4(b) present the corresponding curves, that is, the lifetime dependence of the short-circuit current $J_{\mathrm{sc}}$ and the power conversion efficiency $\eta$. They show that both $J_{\mathrm{sc}}$ and $\eta$ significantly increase when $\tau$ increases up to $50 \mathrm{~ms}$. This means that if other materials instead of $\mathrm{TiO}_{2}(\tau$ takes values
TABLE 4: The values of $J_{\mathrm{sc}}, V_{\mathrm{oc}}, \mathrm{FF}$, and $\eta$ obtained for different electron lifetimes $\tau$.

\begin{tabular}{lcccc}
\hline$\tau(\mathrm{ms})$ & $J_{\mathrm{sc}}\left(\mathrm{mA} / \mathrm{cm}^{2}\right)$ & $V_{\mathrm{oc}}(\mathrm{mV})$ & $\mathrm{FF}$ & $\eta(\%)$ \\
\hline 2 & 9.349 & 766 & 0.833 & 5.968 \\
5 & 10.267 & 787 & 0.825 & 6.674 \\
10 & 11.274 & 804 & 0.831 & 7.532 \\
20 & 12.470 & 822 & 0.828 & 8.482 \\
30 & 13.210 & 832 & 0.824 & 9.053 \\
50 & 14.107 & 845 & 0.818 & 9.737 \\
100 & 15.123 & 863 & 0.823 & 10.742 \\
200 & 15.840 & 881 & 0.827 & 11.544 \\
\hline
\end{tabular}

up to $50 \mathrm{~ms}$ ) are used, the performance parameters of DSSC can be controlled and consequently optimized.

The values for all parameters we obtained from simulation are in good agreement with those reported in the literature for this type of DSSC $[14,19,21,25,30-32]$ which demonstrate that our proposed numerical procedure is valid and versatile. Therefore, it can be used for designing and optimizing DSSCs.

\section{Conclusions}

In this paper we propose a numerical procedure for optimizing the parameters of any type of DSSC, consisting of a simplified physical model and a numerical method capable of solving the system of differential equations resulted from the model.

We applied this procedure on a classical DSSC based on Ru dye by simulating the $J-V$ characteristic and calculating all main parameters, $J_{\mathrm{sc}}, V_{\mathrm{oc}}, \mathrm{FF}$, and $\eta$, and the obtained results are in good agreement with those reported in the literature, which validate our proposed procedure. 


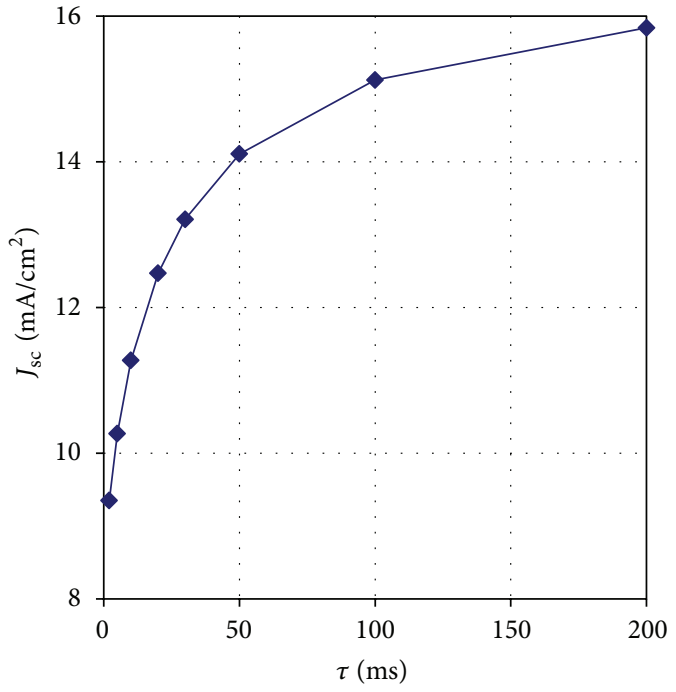

(a)

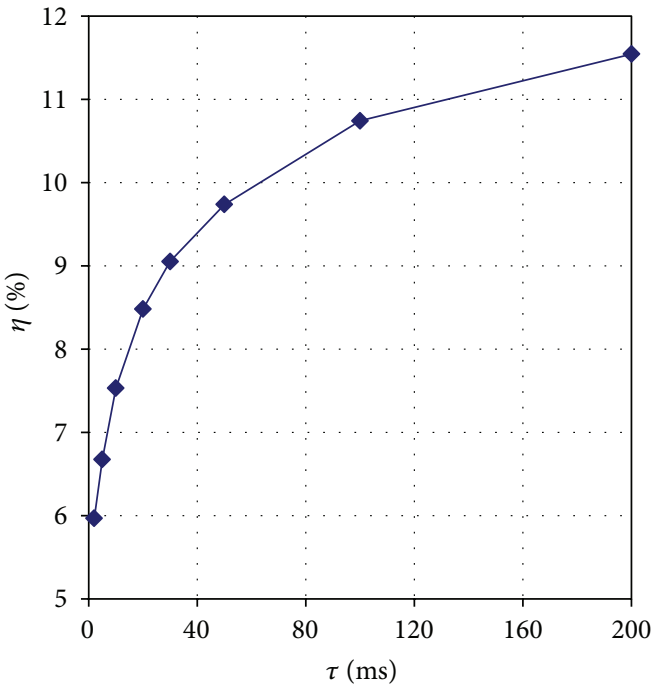

(b)

Figure 4: The lifetime dependence of $J_{\mathrm{sc}}$ (a) and $\eta(\mathrm{b})$, using $\eta_{\text {inj }}=0.95, D=5 \cdot 10^{-5} \mathrm{~cm}^{2} / \mathrm{s}, \beta=0.9$, and $d=20 \mu \mathrm{m}$.

For this, we analyzed the influence of the nature of semiconductor and dye and also the influence of different technological parameters on the performance parameters of DSSCs. Thus, for obtaining the real rate of the absorbed photons $G_{\text {real }}(x)$ we simplified the light absorption and reflection of TCO by introducing the factor $\beta$ and we considered the nature of dye by using the specific absorption coefficient $\alpha(\lambda)$. We analyzed the influence of $\mathrm{TiO}_{2} /$ semiconductor thickness and electron lifetime in the conduction band on the main cell parameters. We showed that the increase of $\mathrm{TiO}_{2}$ semiconductor thickness over the optimal thickness of $15 \mu \mathrm{m}$ does not influence the $J_{\mathrm{sc}}$ and $\eta$ values $\left(J_{\mathrm{sc}}=12.601 \mathrm{~mA} / \mathrm{cm}^{2}\right.$ and $\eta=8.589 \%$ ). We obtained a similar result for the electron lifetime higher than $40-50 \mathrm{~ms}$. The obtained results in good agreement with the literature validate our numerical procedure. The analysis made on this classical DSSC based on $\mathrm{TiO}_{2}$ with Ru dye can be extended to any other DSSCs.

The proposed numerical procedure allows a comprehensive analysis of the performance parameters of DSSCs and permits the development of a numerical simulation platform for designing and optimizing any type of DSSCs.

\section{Conflict of Interests}

The authors declare that there is no conflict of interests regarding the publication of this paper.

\section{Acknowledgment}

This work was partially supported by the Romanian National Authority for Scientific Research through the CNCSUEFISCDI under Contract no. PN II-PT-PCCA-9/2012.

\section{References}

[1] H. S. Jung and J. K. Lee, "Dye sensitized solar cells for economically viable photovoltaic systems," The Journal of Physical Chemistry Letters, vol. 4, no. 10, pp. 1682-1693, 2013.

[2] G. Conibeer, M. Green, R. Corkish et al., "Silicon nanostructures for third generation photovoltaic solar cells," Thin Solid Films, vol. 511, pp. 654-662, 2006.

[3] R. R. King, D. C. Law, K. M. Edmondson et al., "40\% efficient metamorphic GaInP/GaInAs/Ge multijunction solar cells," Applied Physics Letters, vol. 90, no. 18, Article ID 183516, 2007.

[4] J. G. J. Adams, B. C. Browne, I. M. Ballard et al., "Recent results for single-junction and tandem quantum well solar cells," Progress in Photovoltaics, vol. 19, no. 7, pp. 865-877, 2011.

[5] V. Iancu, M. R. Mitroi, A.-M. Lepadatu, I. Stavarache, and M. L. Ciurea, "Calculation of the quantum efficiency for the absorption on confinement levels in quantum dots," Journal of Nanoparticle Research, vol. 13, no. 4, pp. 1605-1612, 2011.

[6] B. O’Regan and M. Grätzel, "A low-cost, high-efficiency solar cell based on dye-sensitized colloidal $\mathrm{TiO}_{2}$ films," Nature, vol. 353, no. 6346, pp. 737-740, 1991.

[7] A. Yella, H.-W. Lee, H. N. Tsao et al., "Porphyrin-sensitized solar cells with cobalt (II/III)-based redox electrolyte exceed 12 percent efficiency," Science, vol. 334, no. 6056, pp. 629-634, 2011.

[8] M. Grätzel, "Dye-sensitized solar cells," Journal of Photochemistry and Photobiology C, vol. 4, no. 2, pp. 145-153, 2003.

[9] L. Han, A. Islam, H. Chen et al., "High-efficiency dye-sensitized solar cell with a novel co-adsorbent," Energy and Environmental Science, vol. 5, no. 3, pp. 6057-6060, 2012.

[10] X. Yang, M. Yanagida, and L. Y. Han, "Reliable evaluation of dyesensitized solar cells," Energy and Environmental Science, vol. 6, no. 1, pp. 54-66, 2013.

[11] T. Oda, S. Tanaka, and S. Hayase, "Differences in characteristics of dye-sensitized solar cells containing acetonitrile and ionic liquid-based electrolytes studied using a novel model," Solar 
Energy Materials and Solar Cells, vol. 90, no. 16, pp. 2696-2709, 2006.

[12] J. Ferber, R. Stangl, and J. Luther, "Electrical model of the dyesensitized solar cell," Solar Energy Materials and Solar Cells, vol. 53, no. 1-2, pp. 29-54, 1998.

[13] L. Peter, "Transport, trapping and interfacial transfer of electrons in dye-sensitized nanocrystalline solar cells," Journal of Electroanalytical Chemistry, vol. 599, no. 2, pp. 233-240, 2007.

[14] M. Berginc, M. Filipic, U. O. Krašovec et al., "Optical and electrical modelling and characterization of dye-sensitized solar cells," Current Applied Physics, vol. 10, no. 3, pp. S425-S430, 2010.

[15] J. Bisquert and I. Mora-Seró, "Simulation of steady-state characteristics of dye-sensitized solar cells and the interpretation of the diffusion length," Journal of Physical Chemistry Letters, vol. 1, no. 1, pp. 450-456, 2010.

[16] J. Halme, P. Vahermaa, K. Miettunen, and P. Lund, "Device physics of dye solar cells," Advanced Materials, vol. 22, no. 35, pp. E210-E234, 2010.

[17] M. Onodera, K. Ogiya, A. Suzuki et al., "Modeling of dyesensitized solar cells based on $\mathrm{TiO}_{2}$ electrode structure model," Japanese Journal of Applied Physics, vol. 49, no. 4, Article ID 04DP10, 2010.

[18] L. Andrade, J. Sousa, H. Aguilar Ribeiro, and A. Mendes, "Phenomenological modeling of dye-sensitized solar cells under transient conditions," Solar Energy, vol. 85, no. 5, pp. 781-793, 2011.

[19] S. Wenger, M. Schmid, G. Rothenberger, A. Gentsch, M. Grätzel, and J. O. Schumacher, "Coupled optical and electronic modeling of dye-sensitized solar cells for steady-state parameter extraction," Journal of Physical Chemistry C, vol. 115, no. 20, pp. 10218-10229, 2011.

[20] D. Gentilini, A. Gagliardi, and A. D. Carlo, "Dye solar cells efficiency maps: a parametric study," Optical and Quantum Electronics, vol. 44, no. 3-5, pp. 155-160, 2012.

[21] K. Nithyanandam and R. Pitchumani, "Analysis and design of dye-sensitized solar cell," Solar Energy, vol. 86, no. 1, pp. 351$368,2012$.

[22] P. H. Joshi, D. P. Korfiatis, S. F. Potamianou, and K. A. Th. Thoma, "Optimum oxide thickness for dye-sensitized solar cells-effect of porosity and porous size: a numerical approach," Ionics, vol. 19, no. 3, pp. 571-576, 2013.

[23] M. R. Mitroi and L. Fara, "Organic solar cells modeling and simulation," in Advanced Solar Cell Materials: Technology, Modeling and Simulation, L. Fara and M. Yamaguchi, Eds., pp. 120-137, IGI Global, 2013.

[24] D. M. B. P. Ariyasinghe, H. M. N. Bandara, R. M. G. Rajapakse, K. Murakami, and M. Shimomura, "Improved performance of dye-sensitized solar cells using a diethyldithiocarbamatemodified $\mathrm{TiO}_{2}$ surface," Journal of Nanomaterials, vol. 2013, Article ID 258581, 6 pages, 2013.

[25] J. S. Agnaldo, J. C. Cressoni, and G. M. Viswanathan, "Universal aspects of photocurrent-voltage characteristics in dyesensitized nanocrystalline $\mathrm{TiO}_{2}$ photoelectrochemical cells," Physical Review B, vol. 79, no. 3, Article ID 035308, 2009.

[26] M. Grätzel, "Photoelectrochemical cells," Nature, vol. 414, no. 6861, pp. 338-334, 2001.

[27] "Solving Boundary Value Problems in MathCad," 2013, http://www.chem.mtu.edu / tbco/cm3450/bvp.pdf .

[28] F. Gao, Y. Wang, D. Shi et al., "Enhance the optical absorptivity of nanocrystalline $\mathrm{TiO}_{2}$ film with high molar extinction coefficient ruthenium sensitizers for high performance dyesensitized solar cells," Journal of the American Chemical Society, vol. 130, no. 32, pp. 10720-10728, 2008.

[29] "ASTM G173-03 Reference Spectra Derived from SMARTS v. 2. 9. 2," 2012, http://rredc.nrel.gov/solar/spectra/am1.5/ ASTMG173/ASTMG173.html.

[30] B. E. Hardin, E. T. Hoke, P. B. Armstrong et al., "Increased light harvesting in dye-sensitized solar cells with energy relay dyes," Nature Photonics, vol. 3, no. 7, pp. 406-411, 2009.

[31] C.-H. Lee, K.-Y. Liu, S.-H. Chang et al., "Gelation of ionic liquid with exfoliated montmorillonite nanoplatelets and its application for quasi-solid-state dye-sensitized solar cells," Journal of Colloid and Interface Science, vol. 363, no. 2, pp. 635-639, 2011.

[32] T. Dittrich, A. Ofir, S. Tirosh, L. Grinis, and A. Zaban, "Influence of the porosity on diffusion and lifetime in porous $\mathrm{TiO} 2$ layers," Applied Physics Letters, vol. 88, no. 18, Article ID 182110, 2006. 

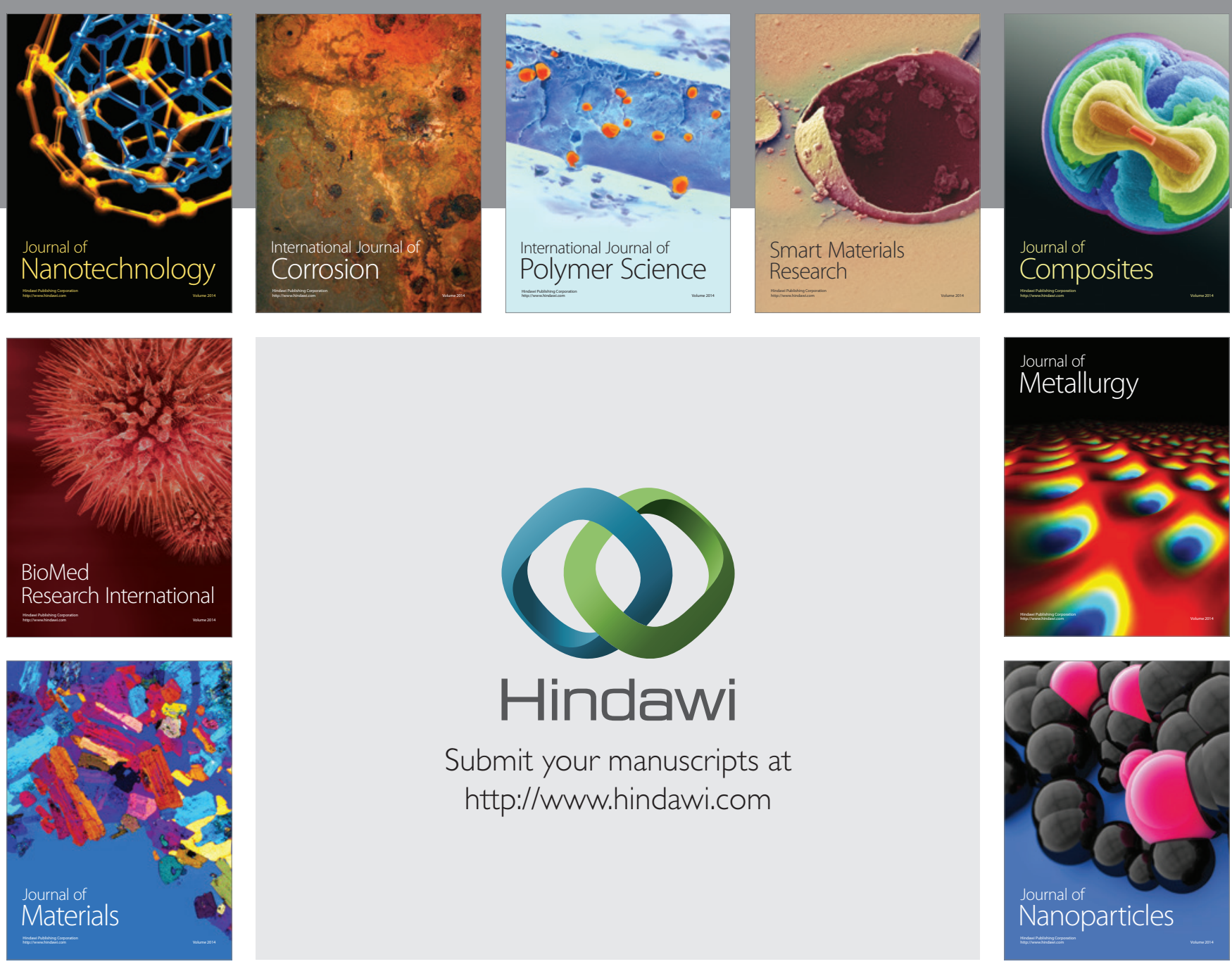

Submit your manuscripts at http://www.hindawi.com
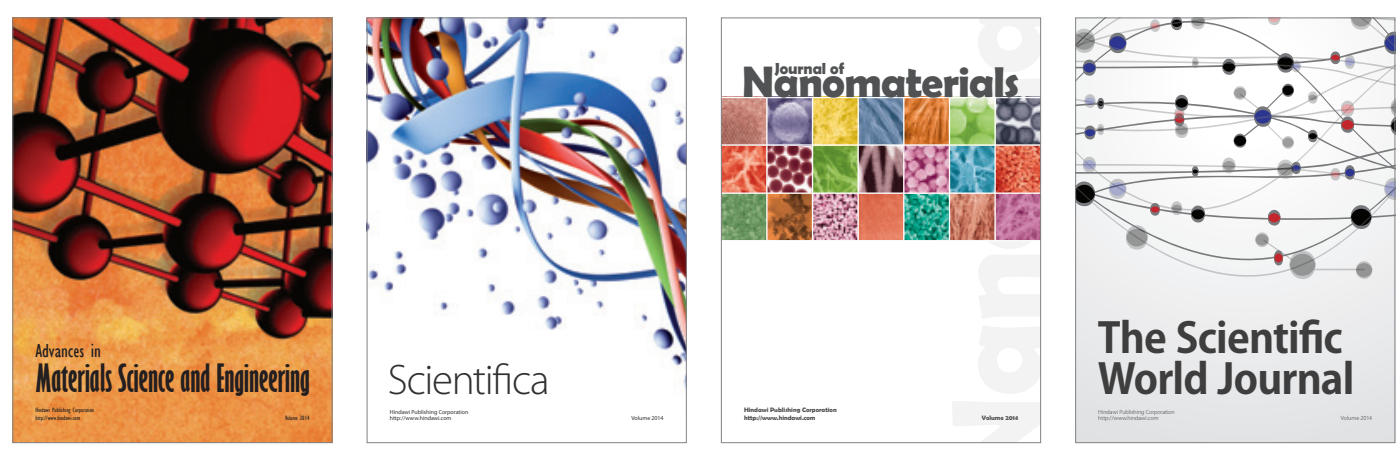

\section{The Scientific World Journal}
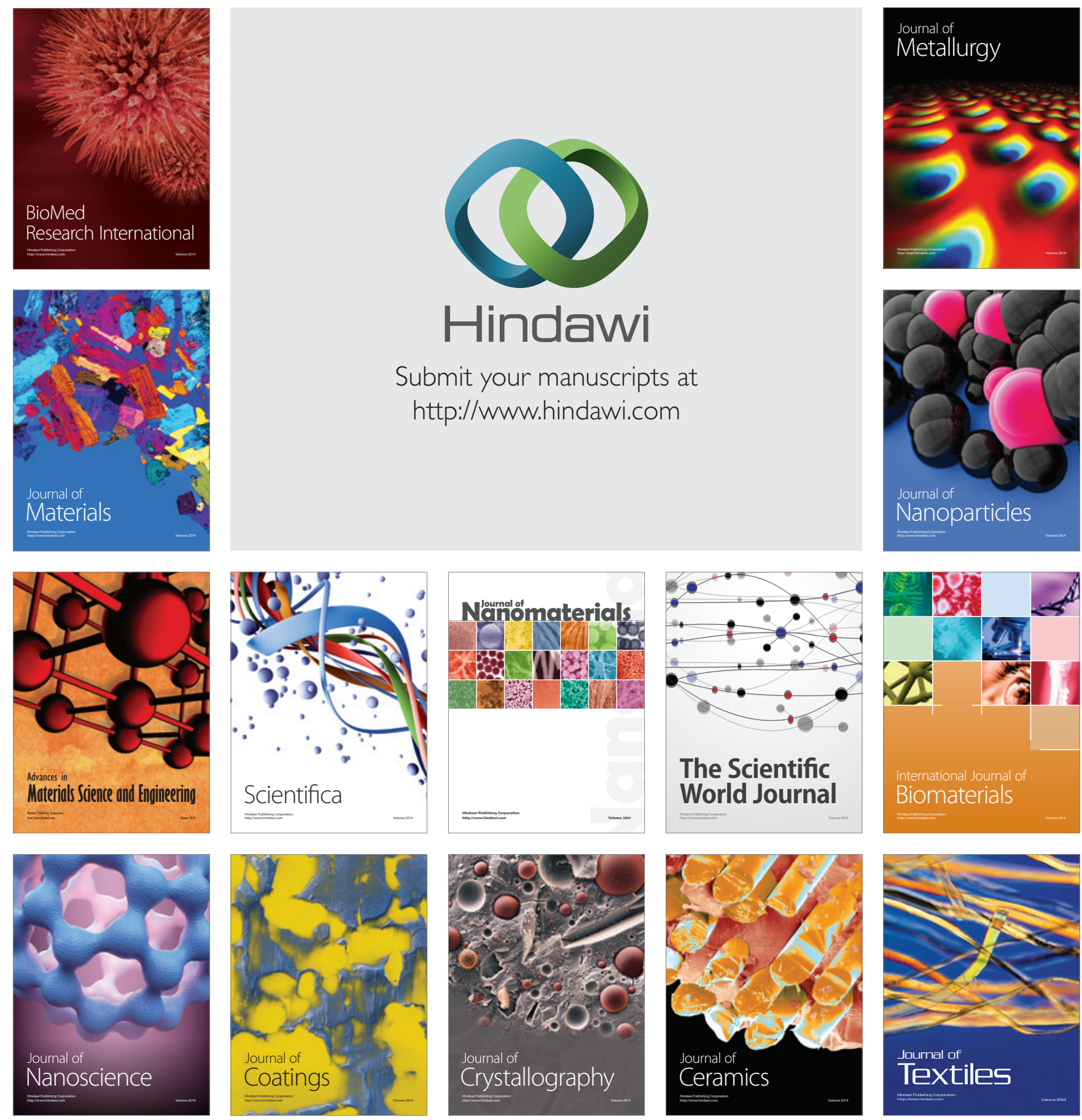